Wilfrid Laurier University

Scholars Commons @ Laurier

Kinesiology and Physical Education Faculty

Publications

Kinesiology and Physical Education

$12-1999$

\title{
Exploring Effects of School Sport Experiences on Sport Participation in Later Life
}

James Curtis

University of Waterloo

William McTeer

Wilfrid Laurier University, bmcteer@wlu.ca

Philip White

McMaster University

Follow this and additional works at: https://scholars.wlu.ca/kppe_faculty

\section{Recommended Citation}

Curtis, James; McTeer, William; and White, Philip, "Exploring Effects of School Sport Experiences on Sport Participation in Later Life" (1999). Kinesiology and Physical Education Faculty Publications. 4.

https://scholars.wlu.ca/kppe_faculty/4

This Article is brought to you for free and open access by the Kinesiology and Physical Education at Scholars Commons @ Laurier. It has been accepted for inclusion in Kinesiology and Physical Education Faculty Publications by an authorized administrator of Scholars Commons @ Laurier. For more information, please contact scholarscommons@wlu.ca. 


\title{
Exploring Effects of School Sport Experiences on Sport Participation in Later Life
}

\author{
James Curtis \\ University of Waterloo
}

\author{
William McTeer \\ Wilfrid Laurier University
}

\author{
Philip White \\ McMaster University
}

\begin{abstract}
This paper presents findings on the relationship between high school sport participation and involvement in sport as adults. The data are provided by a survey of a large representative national sample of adult Canadians. For different age subgroups among women and men, we tested the school sport experiences hypothesis that sport involvement during the high school years contributes to later adult involvement in sport. The measurement of sport involvement in the high school years is concerned with intramural and inter-school activities. Adult sport activity has three measures: sport involvement per se, involvement in an organized setting, and competitive involvement. The results are consistent with the school experiences hypothesis. High school sport involvement, for inter-school sport activities, is a comparatively strong predictor of adult sport involvement. The effects of high school involvement persist after controlling for correlated social background factors. Moreover, the effects of school sport experiences hold across age and gender subgroups. Although diminished with temporal distance from the high school years, the effects of high school involvement nonetheless extend even to respondents aged 40-59 (i.e., those approximately 22 to 42 years beyond their school years) among both genders. Interpretations of the results are discussed.
\end{abstract}

Cet article porte sur les résultats d'une étude sur les relations entre la participation sportive à l'école secondaire et l'implication en sport comme adulte. Les données proviennent d'une enquête nationale à partir d'un échantillon représentatif d'adultes canadiens. Pour différents sous-groupes d'âge, chez les hommes et chez les femmes, nous vérifions l' «hypothèse des expériences sportives scolaires» selon laquelle l'implication en sport pendant les années d'études secondaires contribue à l'implication en sport plus tard comme adulte. La mesure de l'implication sportive au secondaire est associée avec les activités intra-murales et interscolaires. L'activité sportive adulte a trois mesures : l'implication en sport comme telle, l'implication en situation organisée et l'implication en compétition. Les résultats sont compatibles avec l'hypothèse des expériences sportives scolaires. L'implication au secondaire dans des activités sportives inter-scolaires est un prédicteur puissant de l'implication sportive adulte. Les effets de l'implication sportive au secondaire persistent après avoir contrôlé

J. Curtis is with the Department of Sociology and the Faculty of Applied Health Studies at the University of Waterloo, Waterloo, Ontario, N2L 3G1. W. McTeer is with the Department of Kinesiology and Physical Education at Wilfrid Laurier University, Waterloo, Ontario, N2L 3C5. P. White is with the Department of Kinesiology at McMaster University, Hamilton, Ontario, L8S 4K1. 
pour les facteurs des antécédents sociaux. De plus, les effets des expériences sportives scolaires sont présents pour tous les sous-groupes d'âge et de genre. Quoique diminués par la distance temporelle d'avec les années d'études secondaires, les effets de l'implication sportive au secondaire sont tout de même présents chez les répondants et les répondantes âgés de 40 à 59 ans (de 22 à 42 ans après le secondaire). Les interprétations des résultats sont discutées.

The many positive consequences of adult participation in sport and physical activity have become well known. The positive consequences have been shown to be of various types-physical, psychological, sociological, and cultural (e.g., see the reviews in Bouchard, Shepard, Stephens, Sutton, \& McPherson, 1990; Bouchard, Shepard, \& Stephens, 1994; Curtis \& Russell, 1997; Quinney, Gauvin, \& Wall, 1994; and Spirduso, 1995). It is believed that there are few negative consequences for individuals except where the involvement is excessively frequent, too rigorous, or overly competitive (see, e.g., Nicholl, Coleman \& Brazier, 1994; Nicholl, Coleman, \& Williams, 1995; White, Young, \& Gillett, 1995). As might be expected, because of the positive consequences of sport and physical activity among adults, much attention has been given to how often adults participate, and how to increase their participation and adherence to involvement (e.g., the literature reviewed in Curtis \& Russell, 1997, chaps. 1-3). There are, however, suggestions here and there in the literature on the sociology of sport and physical activity that those interested in increasing physical activity among adults would do well also to direct careful attention to promotional activities among children and youth. The results of various studies suggest that having early experiences with sport and physical activity in school positively predicts sport participation among young adults, and, perhaps, even participation in later years (e.g., Bucher, 1974; Howell \& McKenzie, 1987; Kelly, 1980; Malina, 1996; Montoye, Van Huss, \& Zuidema, 1959; Morgan \& Montoye, 1984; Paffenburger, Hyde, Wing, \& Hsieh, 1986; Powell \& Dysinger, 1987; Rees, Andres, \& Howell, 1986; Vanreusel et al., 1997; Watkins, 1983; White \& Curtis, 1990; Yang, 1997). For present purposes, we label this the school sport experiences hypothesis.

The research evidence on effects of childhood and youth sport participation upon adult sport activities remains quite partial, however. For example, it remains unclear whether the positive effects of early participation extend over many years of life, and whether the patterns are the same for women and men. Available longitudinal panel studies (where the same respondents are interviewed at different points in time over a period of years) have often focused on males, instead of dealing with both genders, and few cover a very long time period over the lifecycle. Further, little is known about whether the positive effects of early sport experience on later adult involvement help, to some extent, to "counteract" or "over-ride" structural impediments to participation common among women and older people.

There are, of course, various theoretical approaches in sociology which suggest that physical activity and other forms of social activities, once started, are likely to be continued as long as (a) they remain rewarding, (b) opportunities for participation are available, and (c) competing rewarding activities do not interfere. Primary among these is the theoretical approach called Continuity Theory, which is generally applied to activities during later adulthood (e.g., Atchley, 1989; McPherson, 1998, chaps. 3 \& 9). As individuals age, it is argued, they generally strive to maintain continuities in lifestyles, because activities once regularly undertaken continue to be rewarding and valued. Further, other theories of socialization 
suggest that identities and patterns of behavior among adults of all ages are often acquired early in the lifecycle through processes of imitation, practice, and reinforcement in social interaction with others (e.g., Bandura, 1969; Bandura \& Walters, 1963; Csikszentmihalyi, 1997; Nixon \& Frey, 1996; Wankel, 1997). Identities acquired in this way are believed to be rather persistent and resistant to change. Thus, involvement with sport early in one's life should, other things being equal, lead one to be more involved in such activities compared with those without the early experiences. For how long over the lifecycle such links of early sport socialization and later sport activity may be expected to persist, however, is very much an open question because of the scarcity of data on individuals over long time spans. Presumably such links will persist for activities where the three conditions listed above are met but tend not to persist where one or more of these conditions are not met.

Our purpose in this paper is to present newly available data from a large Canadian national sample on the consequences of experiences with high school sport for sport participation in adulthood. Retrospective questions on school sport involvement and the large sample size allowed tests of effects of school sport experience for different age cohorts and for each gender. For older respondents, these tests covered a broad sweep of time in the lifecycle. We test for the effects of early experience with sport among age subgroups extending to those 60 and over. We ask whether the effects of school-age experiences can be shown to obtain in similar ways across age categories and for each gender. Further, our analyses allow us to assess the relative explanatory import of early experiences with sport and other social background characteristics.

\section{Previous Studies of Effects of School Sport Experiences}

When researchers have looked at the impact of sport participation as a child and youth upon later sport participation, the results generally show a positive correlation (Bucher, 1974; Howell \& McKenzie, 1987; Kelly, 1980; Malina, 1996; Montoye et al., 1959; Morgan \& Montoye, 1984; Paffenburger et al., 1986; Powell \& Dysinger, 1987; Rees et al., 1986; van Mechelen \& Kemper, 1995; Vanreusel et al., 1997; Watkins, 1983; White \& Curtis, 1990; Yang, 1997), but not always (cf., Powell \& Dysinger, 1987). The strength of the association varies markedly across studies probably as a result of the different procedures used. Particularly, the measurement of early and later involvement varies greatly from study to study. Also, the samples employed in these studies are often local "convenience" samples with varying compositions in terms of age, social class, ethnicity, and rural-urban residence. Seldom are they representative national samples that would allow us to assess the generalizability of the results to the overall population. This is particularly the case when the studies are panel studies as opposed to retrospective studies of cross-sectional samples. Further, the studies seldom involve detailed multivariate analyses which take into account the confounding effects of social background factors that are correlated with both earlier and later sport participation (e.g., reviews of studies by Howell \& McKenzie, 1987; Malina, 1996; Powell \& Dysinger, 1987).

To consider one example of the problem of the lack of controls, the results of the United States Adult Fitness Survey, a national cross-sectional survey of a representative sample of over 3,500 adults, showed that those who had participated in 
competitive organized sports during the school years were more likely to be involved in sport and exercise as adults than those who had not participated (Bucher, 1974; Howell \& McKenzie, 1987). The same was true for comparisons of those who had taken some physical education classes and those who had not. However, the results, as reported, have to be partially confounded by the effects of age and sex. Older people and females generally report lower levels of school sport participation and less current sport involvement than younger people and males. Therefore, it is impossible to accurately estimate the effects of early sport participation upon later involvement without controlled comparisons employing sex and age, as well as other relevant social background factors.

Howell and McKenzie's (1987) work provides an important exception to both the common lack of controlled comparisons and the heavy reliance on crosssectional data. Using a U.S. national sample of high school students interviewed in 1955 and recontacted in 1970, they showed that varsity and nonvarsity sport participation in high school increased adult sport involvement. Even with this study, though, we must be cautious about interpreting the results. The heavy attrition between Time 1 and Time 2 poses problems. It is unclear, for example, whether respondents who are now active in sport activity (and probably were more active earlier) were more easily traced by interviewers (see also Malina's 1996 review of panel studies). This problem of attrition in panel studies is a common one that is avoided with retrospective studies of cross-sectional samples, the procedure employed in the present analyses.

Another exception to the lack of controlled comparisons, and one dealing with the Canadian case, is White and Curtis's (1990) study. They used multivariate analyses of retrospective data from a national adult sample for Canada from 1976 and showed that participation in the high school years in physical education classes, in intramural sports, and in inter-school sports were all positively related to rates of adult participation in recreational sport activities and involvement in organized competitive activities (cf. Curtis \& White, 1992). These findings held across both genders and for two major Canadian linguistic groups. The present analyses will allow us to update and extend these earlier analyses for Canadians, with particular attention to comparisons across age groups.

Malina (1996) has recently summarized the results of available panel studies. He shows that (a) few studies cover a long time span in the lifecycle on their own, (b) they involve differing types of samples (generally, convenience samples), and (c) they employ varying indicators of sport and physical activity and methods of analysis. As a result, correlations of earlier and later involvement in sport and physical activity vary considerably across studies. However, these studies can be juxtaposed to give a tentative picture of effects over the lifecycle. When this is done, Malina (1996) reports, "it appears that physical activity tracks at low to moderate levels during adolescence, from adolescence into adulthood and across various ages in adulthood" (p. 55). Generally, the longer the period of the age comparison, covering adolescence to adulthood, the lower the correlation. For example, a study of Dutch youth (van Mechelen \& Kemper, 1995) showed correlations ranging from .05 to .20 for comparisons of physical activity from 13 years of age into the late $20 \mathrm{~s}$ and mid $30 \mathrm{~s}$.

In the few studies that have examined the relative strengths of predictors of adult sport involvement, sport activity as a youth sometimes functions as a better predictor than social background factors such as education, income, and marital 
status. This is true, for example, of the results of two of the available longitudinal panel studies. Vanreusel et al. (1997) reported such patterns for research with a small sample of males studied from ages 13 to 35 in Belgium. Similar results were presented by Yang (1997) for a 12-year follow-up of a sample of Finnish youths. Further, parallel findings were derived from White and Curtis's (1990) study of retrospective data from a cross-sectional survey of Canadian adults. Education and income were positively associated with different measure of sport participation, and males and younger people participated more than females and older people (see also White, Curtis, \& McPherson, in press). The majority ethnic group, English Canadians, was more involved in competitive sport but not sport in general. We expected similar patterns of results to obtain in the 1992 data used in the present analyses.

\section{Data Source and Procedures}

\section{Data Source}

The data for our analyses were taken from the 1992 General Social Survey, conducted by Statistics Canada, the federal government's major data-gathering agency. This survey asked people how they used their time, including whether there was involvement in sport activities. The survey involved telephone interviews with a representative sample of Canadian adults $(N=9,815)$. Our working sample for the present analyses was restricted to respondents who were 20 years of age and older, and who reported that they were not now attending school as a main activity $(N=8,560)$. This working sample was used to assure that all respondents had spent their school years in the Canadian school system and that adult sport involvement was measured only for those who had completed their schooling.

\section{Analyses and Measures}

Our method was secondary analysis of the extant data. As usual in secondary analysis, we had no control over the survey questions asked. We would have preferred, if possible, to have obtained more detail on respondents' early sport activities, including activities outside the school setting. However, the survey did provide reports on involvement in two potentially important aspects of organized high school sport, along with information on the current activities of the respondents. Further, it is fortunate that the data are from a large nationally representative sample. First, as we suggested above, this is important because many of the previous panel studies examining the relationship between participation in high school sport and adult sport involvement have had high attrition levels, particularly where a time span of any length was involved. And, some of these studies have employed convenience samples. These characteristics of the studies stand in the way of generalization of the findings to the general population. Second, the 1992 survey is large enough to allow detailed analyses across age subgroups of each gender. Also, the data include rich information on the social background characteristics of respondents. This fact, along with the sample size, allowed us to control for effects of education, income, language group, marital status, and region of the country.

The measures of adult sport involvement were constructed from responses to the following question: During the past 12 months, did you regularly participate 
in any sports such as volleyball, bowling, or skiing? If the respondent answered yes, she or he was asked to list those sports in which she or he had participated (to a maximum of five). For each sport named, the respondent was asked the following questions: Was this organized through a club, a community recreation program, a league, or a provincial sport organization? Participants in such organized activities were also asked, Did you participate in a competition and/or tournament in the past 12 months? The three dependent variables for our analyses were constructed from the above questions. For each respondent, a measure of sport involvement in general was created by summing the number of sports that each respondent said she or he participated in during the previous 12 months. Two additional measures were created: organized sport involvement for the number of sports that the respondent reported participating in as a member of an organized club, recreation program, league, or provincial sport organization, and competitive sport involvement for the number of sports played at the competitive level by those who reported organized sport involvement. These measures were subsequently collapsed to a range of 0 to 2 (for no sports, one sport, or two or more sports) because of the small sample size for those playing more than two organized or competitive sports.

The independent measure, school sport experience, was derived from the responses to the following questions: When you were at school, did you ever participate in organized school sport other than in physical education classes? and Were you ever involved in competition between schools? This yielded a measure with a first category of respondents with neither type of involvement beyond physical education classes, a second category of those involved in organized school sport but not inter-school competition, and a third category of people involved in both organized school sport and inter-school competition.

The following control variables were employed in the analyses: education (less than high school graduation; high school graduation; some post-secondary, community college/trade school diploma; university degree); income (five categories); age (five categories ranging from 20-29 years to 60 years and older); marital status (currently married or single); region of the country of residence; language spoken most often at home (English or French); and sex of the respondent. These factors were introduced as statistical or contingency controls because preliminary analyses, as well as previous studies, showed them to be correlated with the dependent and independent measures (for results for Canada, see White \& Curtis 1984, 1990).

Our primary data analysis procedure was Multiple Classification Analysis (MCA). This procedure assesses the effects of either noncontinuous or continuous predictor variables on a dependent variable, while simultaneously controlling for the effects of other variables. MCA yields mean scores on the dependent variable, both unadjusted and adjusted for the effects of the control variables and statistical interactions, and provides an $F$ test for statistical significance. The procedure also generates eta and beta coefficients for each predictor variable, for the zero-order and controlled analyses, respectively. The betas (partial correlation ratios), when squared, roughly indicate the proportion of the total variance in the dependent variable accounted for by each predictor after partialing out the effects of the other predictors (see Andrews, Morgan, Sonquist, \& Klem, 1973). We also present some cross-tabular analyses for the extent of involvement in high school sport and current sport activities. 


\section{Findings}

\section{Distribution of High School Sport Participation}

Table 1 shows the proportions, by gender and age levels, who had played organized sports in their high schools and who were involved in competitions between schools. First, as we would expect from the previous literature on gender inequalities, considerably higher proportions of males than females had participated in organized inter-school sport beyond physical education classes $(p<.001)$. However, rates of exclusive involvement in intra-school sport were very similar. Females were much more likely to have had neither type of school sport experience $(p<.001)$. Nearly $50 \%$ (47.1) of female and only about $30 \%$ (31.9) of males had no involvement in organized inter- and intra-school sport during the high school years. Nearly $60 \%$ (56.7) of males and $40 \%$ (38.5) of females have some experience with inter-school competition in their high school years.

Table 1 Percent With High School Sport Experience of Two Types and With Current Sport Involvement (Three Measures) for Subsamples Defined by Gender and Age Categories: National Sample Data for Canada, 1992

\begin{tabular}{|c|c|c|c|c|c|c|c|}
\hline & \multirow[b]{2}{*}{$(N)^{\mathrm{a}}$} & \multicolumn{3}{|c|}{ High school sport } & \multicolumn{3}{|c|}{ Current adult sport } \\
\hline & & $\begin{array}{c}\text { None } \\
(\%)\end{array}$ & $\begin{array}{l}\text { Intra- } \\
\text { school } \\
(\%)\end{array}$ & $\begin{array}{c}\text { Inter- } \\
\text { school } \\
(\%)\end{array}$ & $\begin{array}{c}\text { All } \\
\text { forms } \\
(\%)\end{array}$ & $\begin{array}{l}\text { Organized } \\
\text { sport } \\
(\%)\end{array}$ & $\begin{array}{c}\text { Com- } \\
\text { petitive } \\
\text { sport } \\
(\%)\end{array}$ \\
\hline Total sample & $(8,560)$ & 40.4 & 13.1 & 46.6 & 42.6 & 19.2 & 12.3 \\
\hline \multicolumn{8}{|l|}{ Genders } \\
\hline Females & $(4,760)$ & 47.1 & 14.4 & 38.5 & 35.6 & 14.5 & 7.9 \\
\hline Males & $(3,800)$ & 31.9 & 11.4 & $56.7 * * *$ & $51.3 * * *$ & $25.2 * * *$ & $17.8 * * *$ \\
\hline \multicolumn{8}{|c|}{ Gender by age level } \\
\hline \multicolumn{8}{|l|}{ Females } \\
\hline $20-29$ & $(967)$ & 36.0 & 13.4 & 50.6 & 44.8 & 17.6 & 9.4 \\
\hline $30-39$ & $(1,224)$ & 43.5 & 13.5 & 43.0 & 43.6 & 17.5 & 9.9 \\
\hline $40-59$ & $(1,306)$ & 47.7 & 14.2 & 38.1 & 35.1 & 13.2 & 7.3 \\
\hline 60 and over & $(1,263)$ & 58.6 & 16.2 & $25.3 * * *$ & $20.1 * * *$ & $8.5 * * *$ & $3.9 * * *$ \\
\hline \multicolumn{8}{|l|}{ Males } \\
\hline $20-29$ & $(757)$ & 25.5 & 12.1 & 62.3 & 68.1 & 37.5 & 26.9 \\
\hline $30-39$ & $(1,123)$ & 27.9 & 11.1 & 61.0 & 60.6 & 30.9 & 23.1 \\
\hline $40-59$ & $(1,194)$ & 32.2 & 11.0 & 56.8 & 44.8 & 19.2 & 11.9 \\
\hline 60 and over & (716) & 44.3 & 11.9 & $43.9 * * *$ & $25.6 * * *$ & $10.6 * * *$ & $7.3 * * *$ \\
\hline
\end{tabular}

${ }^{a}$ These are the smallest $N$ s for any of the analyses with different dependent measures. $* * * p<.001$. 
Second, older respondents reported less participation in the two types of high school sport involvement than younger respondents, for each gender $(p<$ .001 for each analysis). This is to be expected because smaller proportions of the older cohorts than the recent cohorts would have completed high school, and the sport programs of Canada's high schools have grown and broadened over time. The involvement rates were linearly related to age. For example, younger females (age 20-29) showed 50.6\% with some involvement in inter-school competitions compared with $25.3 \%$ for the oldest category (60 and over) of females. The counterpart results for males $20-29$ and 60 and over were $62.3 \%$ and $43.9 \%$, respectively.

\section{Distribution of Current Sport Involvement}

Current levels of involvement in sport among those in the adult sample, by gender and age, are also reported in Table 1 . The findings show, again as would be expected, that for all three measures, males were more likely to be involved than females $(p<.001$ in each analysis). Although not reported in the table, the findings of higher sport participation among males than females also held within most age categories $(p<.05$ for the analyses within all age subgroups except for organized sport and competitive sport among those 60 and older, where the patterns were not statistically significant).

Further, age was inversely related to adult involvement in sport in general, organized sport, and competitive sport $(p<.001$ for each measure within each gender). Among males, older respondents clearly participated less than younger respondents, regardless of sport context. The relationships were all inverse and linear, as Table 1 shows. The declines in involvement with age were not as marked for females as for males. The differences between the two younger female age categories (20-29 and 30-39) were relatively small. Women age 40-59 and 60 and over, though, tended to be considerably less involved than their younger counterparts ( $p<.001$ for all comparisons).

\section{Relationships of High School Participation and Adult Involvement}

In Table 2, MCA analyses are presented showing the relationships between sport participation during the high school years and current sport involvement as an adult before and after statistical controls. The results are presented for each gender overall and for four age levels within each gender. Consistent with the school sport experience hypothesis, high school sport involvement and adult sport involvement were positively associated; those with inter-school sport competition experience were more involved as adults compared with either those with only intra-school sport experience and those with neither of these types of school participation. For example, in the first column of the table (labeled $N C$, for no controls), the mean score for sport involvement in general among females with inter-school sport competition was .15 over the overall mean, compared with .08 below the mean for intra-school competitors only and .10 below the mean for those with neither type of school participation. Counterpart figures for males overall (six panels lower in the table in the first NC column) were .14 above the mean for inter-school competitors, versus .21 and .19 below the mean for, respectively, intra-school competitors and those with no school sport experience of either type. 
Table 2 Deviations From the Mean for Current Sport Involvement (Three Measures) by Types of High School Sport Experience Without and With Controls, for Subsamples Defined by Gender and Age Levels

\begin{tabular}{|c|c|c|c|c|c|c|c|}
\hline \multirow[b]{3}{*}{ Subsample } & \multirow[b]{3}{*}{$(N)^{\mathrm{a}}$} & \multicolumn{6}{|c|}{ Types of current sport involvement } \\
\hline & & \multicolumn{2}{|c|}{$\begin{array}{l}\text { Sport involvement } \\
\text { in general }\end{array}$} & \multicolumn{2}{|c|}{$\begin{array}{l}\text { Organized sport } \\
\text { involvement }\end{array}$} & \multicolumn{2}{|c|}{$\begin{array}{c}\text { Competitive sport } \\
\text { involvement }\end{array}$} \\
\hline & & NC & WC & $\mathrm{NC}$ & WC & $\mathrm{NC}$ & WC \\
\hline \multicolumn{8}{|l|}{ Female subsample overall } \\
\hline Mean & & & . & & & & \\
\hline Inter-school competition & $(1,516)$ & .15 & .11 & .09 & .07 & .05 & .04 \\
\hline Intra-school competition only & (539) & -.08 & -.08 & -.06 & -.05 & -.02 & -.02 \\
\hline $\begin{array}{l}\text { Neither } \\
\text { (eta/beta) }\end{array}$ & $(1,777)$ & $\begin{array}{l}-.10 \\
(.16) * * *\end{array}$ & $\begin{array}{l}-.07 \\
(.11)^{* * * *}\end{array}$ & $\begin{array}{l}-.06 \\
(.18) * * *\end{array}$ & $\begin{array}{l}-.04 \\
(.12)^{* * *}\end{array}$ & $\begin{array}{l}-.04 \\
(.13)^{* * * *}\end{array}$ & $\begin{array}{l}-.03 \\
(.10)^{* * *}\end{array}$ \\
\hline \multicolumn{8}{|l|}{ Females aged 20-29 } \\
\hline Mean & & & & & & & \\
\hline Inter-school competition & $(430)$ & .14 & .13 & .10 & .08 & .05 & .03 \\
\hline Intra-school competition only & (110) & -.21 & -.19 & -.14 & -.12 & -.05 & -.04 \\
\hline $\begin{array}{l}\text { Neither } \\
\text { (eta/beta) }\end{array}$ & (298) & $\begin{array}{l}-.13 \\
(.18)^{* * *}\end{array}$ & $\begin{array}{l}-.11 \\
(.16)^{* * *}\end{array}$ & $\begin{array}{l}-.09 \\
(.20)^{* * *}\end{array}$ & $\begin{array}{l}-.08 \\
(.17)^{* * *}\end{array}$ & $\begin{array}{l}-.04 \\
(.11)^{*}\end{array}$ & $\begin{array}{l}-.03 \\
(.09)^{*}\end{array}$ \\
\hline \multicolumn{8}{|l|}{ Females aged 30-39 } \\
\hline Mean & & & & & & & \\
\hline Inter-school competition & $(446)$ & .12 & .11 & .10 & .08 & .07 & .07 \\
\hline Intra-school competition only & (136) & -.06 & -.08 & -.10 & -.10 & -.07 & -.06 \\
\hline Neither & (447) & -.10 & -.09 & -.07 & -.06 & -.05 & -.05 \\
\hline (eta/beta) & & $(.13)^{* * *}$ & $(.12)^{* * *}$ & $(.18)^{* * *}$ & $(.16)^{* * * *}$ & $(.19)^{* * *}$ & $(.17) * * *$ \\
\hline
\end{tabular}


Females aged 40-59

\section{Mean}

Inter-school competition

Intra-school competition only

Neither

(eta/beta)

Females aged 60 and over

Mean

Inter-school competition

Intra-school competition only

Neither

(eta/beta)

Male subsample overall

Mean

Inter-school competition

Intra-school competition only

Neither

(eta/beta)

(157)

(518)

Males aged 20-29

\section{Mean}

Inter-school competition

Intra-school competition only

Neither

(eta/beta)

(140)

(514)

(955)
.52

.08
-.02
-.06
$(.09)^{* *}$

(126)

.02
-.05
-.05

$(.12)^{* * *}$

.31

.09
-.02
-.06
$(.09)^{* *}$

.04
-.00
-.04
$(.08)$

.16

.03
-.01

$-.03$

(.07)

.03
-.01

$-.03$

(.08)

.08

.03

$-.01$

$-.03$

(.08)

.05

$\begin{array}{ll}.08 & .08 \\ -.02 & -.00 \\ -.03 & -.02 \\ (.08)^{* * *} & (.13)^{* * *}\end{array}$

11

.06
-.01
-.02
$(.09) * * *$

.03

.01
-.02

$(.10)^{* * *}$

.83

.14
-.21
-.19
$(.19)^{* * *}$

.10

$-.20$

$-.11$

$(.14)^{* * * *}$

$$
.10
$$

$-.16$

$-.14$

$(.19)^{* * *}$

.34

$$
\begin{aligned}
& .08 \\
& -.14 \\
& -.09 \\
& (.14)^{* * *}
\end{aligned}
$$

.56

$\begin{aligned}(410) & .12 \\ (83) & -.16 \\ (171) & -.20 \\ & (.17)^{* * *}\end{aligned}$

1.12

$\begin{array}{ll}.10 & .11 \\ -.16 & -.20 \\ -.17 & -.16 \\ (.15) * * * & (.18) * * *\end{array}$

.23

$$
\begin{array}{r}
.07 \\
-.12 \\
-.08
\end{array}
$$$$
(.15)^{* * *}
$$

.39

$$
\begin{array}{ll}
.10 & .09 \\
-.17 & -.15 \\
-.16 & -.15 \\
(.20)^{* * *} & (.17)^{* *}
\end{array}
$$




\begin{tabular}{|c|c|c|c|c|c|}
\hline \multirow[b]{3}{*}{ Subsample } & \multirow[b]{3}{*}{$(N)^{\mathrm{a}}$} & \multicolumn{4}{|c|}{ Types of current sport involvement } \\
\hline & & $\begin{array}{l}\text { Sport involvement } \\
\text { in general }\end{array}$ & & & $\begin{array}{c}\text { Competitive sport } \\
\text { involvement }\end{array}$ \\
\hline & & WC & $\mathrm{NC}$ & WC & $\mathrm{NC}$ \\
\hline
\end{tabular}

Males aged 30-39

Mean

Inter-school competition

Intra-school competition only

Neither

(eta/beta)

Males aged 40-59

Mean

Inter-school competition

Intra-school competition only

Neither

(eta/beta)

$\begin{array}{ll}(569) & .14 \\ (105) & -.16 \\ (259) & -.24 \\ & (.20)^{* * *}\end{array}$

Males aged 60 and over

Mean

Inter-school competition

Intra-school competition only

Neither

(eta/beta)
(106)

(305)

$$
\begin{aligned}
& .12 \\
& -.33 \\
& -.10 \\
& (.18)^{* * *}
\end{aligned}
$$

.40

.11
-.14
-.08
$(.15)^{*}$

.99

.11
-.16
-.21
$(.18)$

.72

.41

.09
-.17
-.17
$(.21)^{* * *}$

.08
-.13
-.15
$(.17)^{* *}$

$\begin{array}{ll}.08 & .08 \\ -.29 & -.18 \\ -.04 & -.09 \\ (.14) * * * & (.18)\end{array}$

\begin{tabular}{|c|c|c|}
\hline & \multicolumn{2}{|c|}{16} \\
\hline .06 & .07 & .05 \\
\hline-.15 & -.13 & -.12 \\
\hline-.06 & -.07 & -.06 \\
\hline$(.14)^{* * * *}$ & $(.17) * * *$ & $(.14)^{* * * *}$ \\
\hline
\end{tabular}

$\begin{array}{cc}.07 & .07 \\ -.11 & -.07 \\ -.05 & -.05 \\ (.10) & (.15)^{*}\end{array}$

.25

.15

$\begin{array}{ccc}.04 & .05 & .03 \\ -.07 & -.05 & -.04 \\ -.02 & -.04 & -.03 \\ (.09) & (.15)^{*} & (.10)\end{array}$

Note. All two-way interactions, the results of which are not reported here, were included in the analyses. NC $=$ no controls; WC $=$ controls include age, education, income, marital status, language group, and province of residence.

$* p<.05 ; * * p<.01 ; * * p<.001$. 
Before controls, the etas, showing the strength of the uncontrolled relationship of school sport experience and adult sport involvement, tended to be slightly lower for the older age categories (age 40 and older) than for the younger categories for each gender. Pearson correlations (not reported in the tables) were as follows: Correlations for males for school sport involvement and the three adult involvement measures, respectively, were $.22, .20$, and .19; and the counterpart correlations for females were $.16, .15$, and .15 , each statistically significant at $p<.001$. For males, the correlations for all age levels-20-24, 30-39, 40-59, and 60 and overshowed that school involvement was significantly correlated $(p<.05)$ with each of the three types of adult involvement, with the correlation decreasing somewhat with age. Parallel patterns held for females, but among those 60 and over, only the relationship for organized sport was statistically significant $(p<.05)$.

The analyses with controls (columns labeled "WC" in Table 2) showed very much the same patterns. Among females, school sport experience was a significant predictor of adult involvement for those up to age 40, for all three dependent measures. School sport was also a predictor of sport involvement in general for those age 40-59 $(p<.05)$. Those with inter-school sport experiences were more involved as adults than either those with intra-school organized sport or those with no such experiences with school sport. The latter two categories were lower in adult involvement and indistinguishable from each other (in further analyses not reported in the table, the difference between the two was nonsignificant in the case of each dependent measure for each gender/age subgroup). For respondents age 60 and over, the relationships were in the same direction but not statistically significant. Thus, even among respondents who were 22 years to 42 years past high school, former inter-school sport participants were much more involved than others.

High school sport participation predicted adult involvement even more strongly for males than for females. The betas were .14 or greater for all age categories except 60 and over, where the effects were not significant. In each instance, former high school athletes were more involved as adults. Also, always the more competitive form of high school participation - in other words, inter-school competition - led to increased adult participation. Exclusive involvement in organized intra-school sport did not.

We also checked on the relationships of high school involvement and current adult participation for the age categories 40-49 and 50-59 taken separately (in analyses not presented in Table 2 to save space). We wondered whether the effects of high school participation extended to the older 50-59 age group among the middle-aged category of 40-59. This did occur for males but not for females. For 50-59-year-old females, for the three dependent measures in order, the betas for high school involvement were $.10, .12$, and .05 (all not significant at $p<.05$ ). Among males age 50-59, the counterpart betas were .16, .18, and .14 (all significant at $p<.01)$.

\section{Statistical Interactions}

When we examined the two-way statistical interactions of high school sport participation and age, we found significant interactions for the analyses for each type of adult sport involvement among males ( $p<.01$ for each analysis). Among females, only the interaction for current competitive involvement as a dependent measure was significant $(p<.05)$. In each case of statistically significant interaction, 
the results were such that inter-school sport involvement has a stronger impact upon current sport involvement among younger subgroups, or a decreased influence with increased age.

\section{Relative Effects of School Sport and Other Predictors}

Table 3 reports beta coefficients from the MCA analyses for the female and male subsamples overall (from the analyses providing the panels of Table 2 for females overall and males overall). The betas indicate the relative strengths of the effects on adult sport involvement of the high school participation measure and six other social background characteristics. For both genders, school sport participation was a comparatively strong predictor of all three measures of adult involvement after controls for the effects of the other predictor variables.

Table 3 Betas for School Sport Experience and the Social Background Characteristics as Predictors of Adult Sport Involvement (Three Measures) Among Females and Males

\begin{tabular}{cccc} 
& \multicolumn{3}{c}{ Adult sport involvement } \\
\cline { 2 - 4 } Subsample & Sport & Organized & Competitive \\
involvement & sport & sport \\
in general & involvement & involvement
\end{tabular}

$\begin{array}{llll}\text { Analyses for female subsample } & & & \\ \text { School sport experience } & .11^{* * *} & .12^{* * *} & .10^{* * *} \\ \text { Age } & .13^{* * *} & .04 & .05 \\ \text { Language } & .07 & .04 & .03 \\ \text { Education } & .14^{* * *} & .05 & .02 \\ \text { Income } & .08^{* * *} & .04 & .04 \\ \text { Marital status } & .01 & .02 & .01 \\ \text { Region } & .07^{* * *} & .10^{* * *} & .07 * * * \\ \text { Multiple } R^{2} & .101 & .041 & .027 \\ \text { Analyses for male subsample } & & & \\ \text { School sport experience } & .14^{* * *} & .14^{* * *} & .15^{* * *} \\ \text { Age } & .23^{* * *} & .21 & .18 \\ \text { Language } & .04 & .02 & .08 \\ \text { Education } & .16^{* * *} & .07 * * & .05 \\ \text { Income } & .12^{* * *} & .11^{* * *} & .10^{* * *} \\ \text { Marital status } & .09^{* * *} & .04 * & .02 \\ \text { Region } & .06 & .05 & .05 \\ \text { Multiple } R^{2} & .170 & .105 & .087 \\ \end{array}$

All two-way interaction, the results of which are not reported here, were included in the analyses. ${ }^{*} p<.05 ; * * p<.01 ; * * * p<.001$. 
Looking at the analyses for the female subsample first, school sport experience was easily the strongest predictor of both organized and competitive involvement as adults ( $\beta=.12$ and $\beta=.10$, respectively). For the predictors of sport involvement in general among females, high school sport $(\beta=.11)$ followed only age $(\beta=.13)$ and education $(\beta=.14)$ in strength (all $p<.001)$. Among the males, school sport background was the second strongest predictor for adult involvement in organized sport and competitive sport $(\beta=.14$, and .15 , respectively), following age $(\beta=.23, .21$, and .18 , respectively).

As would be expected from the previous literature on social background predictors of sport participation, where the background measures had effects, the relationships were as follows: Sport involvement was higher among people with higher education, with higher incomes, living in the more economically advantaged regions, and who are single. Further, as Tables 1 and 2 have already shown, the age relationships were inverse linear relationships.

The relative sizes of the betas indicate that, among the set of social background predictors, the two measures of socioeconomic status (education and income) along with age had the most impact and most consistently so across measures of sport participation. It is important to note that these relationships are not the result of confounding effects from school sport participation; this factor was controlled in the analyses. That is, the table demonstrates that the effects of socioeconomic status and age go beyond effects of associated differences in early school experiences with sport. Differential opportunity structures-opportunities to be involved in sport - by socioeconomic status and age are likely implicated in these effects. The same interpretation likely applies to the regional differences.

Interestingly, among females, current sport participation in competitive sport and organized sport (for which there are comparatively low levels of participation at any age level) is less "structured" than overall involvement in sport. For females, once the comparatively strong effects of early involvement with sport are held constant, only region of the country among the other social background characteristics is a significant predictor of organized participation or competitive participation.

\section{Conclusions}

The results of this study support the school sport experience hypothesis. There was comparatively strong predictive import from inter-school sport participation. The effects were comparatively strong in the sense that they were either about equal in strength to, or stronger than, the effects of six social background factors that sociologists regularly identify as important factors in the structuring of unequal access to sport involvement opportunities-education, income, place of residence, age, marital status, and ethnic background. Moreover, the relatively strong predictive import of competitive sport participation during high school years held across age cohorts and genders. For example, there were significant effects even for persons aged 40-49 and 50-59 who at the time of the study were well past the high school years. However, the significant effects did not extend to those age 60 and older of either gender.

The effects of former school experiences were weaker among older people than among younger people as would be expected from Malina's (1996) review of previous studies showing that there are weaker relationships the longer the time 
period under study. It is unclear why these patterns occur. Only further crosssectional and longitudinal studies of still more adult cohorts will help clarify this. One interpretation is that people who are older tend to focus on, or "specialize" in, types of sport that are different from those they encountered when in high school. Perhaps the types of sport selected by older people are not as similar to former experiences with sport in high school as the sports played in younger adulthood. For this reason, past experiences are less influential among older people. Consistent with this interpretation are results of some other studies (e.g., White \& Curtis, 1984) which suggest that as people involved in sport age, they come to focus on fewer sports and sometimes devote more time to those sports in which they specialize. Some of this specialization may result, of course, from limited opportunities to participate among older people. It also may be the case that it takes considerable time over the lifecycle for other, nonsport activities to successfully compete with sport activities for people's leisure time. The results suggest that continued sport activity occurs, as continuity theory would argue, but that this process is gradually eroded, particularly by age 60 and older. This "erosion" may result from competing rewarding activities, shifting sport interests, or declining opportunities for participation with increased age, or some combination of these factors.

It was the case that participation in the most competitive form of high school sports - inter-school competition-was a predictor of later adult involvement, while participation in organized intra-school activity was not. Indeed, the latter seemed to have little impact compared with not having school sport involvement at all. Again, this pattern obtained across subgroups defined by gender and age. It may be that participants in inter-school activities compared with those involved in other forms of school sport had higher levels of skill, greater interest in sport, more ego involvement, better knowledge of sport, or more time commitment to sport. One or more of these factors, and their effect on continuing sport participation, may account for the stronger effects from inter-school competition.

Where should we go from here in addressing the effects of school sport participation upon adult involvement? There are both practical and research implications of the results. On the practical side, if we assume that the patterns reported here will be repeated among future age cohorts, we should set about trying to assure the inter-school sport involvement of larger proportions of school-age people as soon as possible. The potential benefits of adult sport involvement for health and fitness are too great to do otherwise.

However, it is also the case, concerning the research implications, that we need to know many more of the specifics of how early sport participation operates, how its effects come to obtain. First, we require more information on the effects of different types of high school participation upon later sport involvement-with school-age sport experience defined with more detail and variety than was available in the data analyzed here. We need to better understand the dynamics involved in the differential effects from intra-school participation and inter-school sport involvement. As we suggested, the differential effects may be interpreted to be due to associated differences in skill levels, knowledge, or interest in sport, and their consequences, or the consequences of associated differences in ego commitment and time commitments. The alternative theoretical interpretations just mentioned, framed as working hypotheses, ideally should be tested in research beginning with interviews of cohorts of students and following them over time. 
A reviewer of this paper emphasized that another open research question is whether certain youth sports, but not others, have an influence on later life. The reviewer asked, "Does participation in carryover sports (tennis, swimming, running, weights, golf) make a difference, or is it the love of competing in physical activities that carries over?" Some sports participation early in life may not have positive effects upon later participation. Indeed, the reviewer speculated that "certain youth sports . . . may discourage later participation because of burn out." Again, such hypotheses would best be studied by carefully following cohorts as they age with repeated in-depth interviews.

Further, we require information on the effects, if any, of still other forms of early sport participation - such as sport outside the school system in the wider community, organized and unorganized - and whether the effects vary by gender and age. It is possible that, as in the present study, there are stronger effects for more highly competitive sports (e.g., inter-community and regional competitions) than less competitive sports (e.g., "house league"). In the event that the positive benefits of early experience with sport extend to involvement in nonschool sports, our tests for effects of early sport participation in the present analysis are conservative. They are based only on two dimensions of early sport participation. In this sense, the strength of the effects of school sport, and effects extending into older cohorts, are surprising.

The generalizability of the effects of inter-school sport to other forms of early sport activity remains unclear, though. Certainly the effects do not appear to generalize to intra-school sport. Nevertheless, the effects of involvement in community sport outside the school may constitute a confound in any analysis that looks only at school activities in youth in relation to participation in later life. Likely those most heavily involved in competitive school sport also are more involved in competitive activities in the wider community. If so, any effects from this other involvement would appear to be effects of school involvement. Or, the outside involvement may reinforce effects of school-based sport. Future panel studies should explore these possible explanations as well.

Finally, the relative effects of characteristics that individuals "bring to" early sport involvement of the inter-school type (we suggest better skills, stronger interest in sport, more knowledge, stronger ego commitment, or greater time commitment) versus the effects of positive reinforcement of the early school sport experience remains unclear. Future research must begin to disentangle the relative contributions of selection factors on the one hand and sport socialization processes on the other.

For the above research problems, we would ideally pursue analyses across data obtained from longitudinal panel studies. These studies allow one to measure directly and more extensively sport involvement of different types at different points in the lifecycle, rather than asking people to remember their past involvement, where accurate recall is problematic. Yet, panel studies are expensive and take years to execute, and there is generally considerable sample attrition. Cross-sectional retrospective surveys may not yield detailed measurements of past schoolage sports participation, but they allow us to test the interpretations quickly (i.e., not having to wait for a panel sample to age over time) and with less expense. The present paper suggests the important complementary yield of these types of studies for research topics involving long periods over the lifecycle. 


\section{References}

Andrews, F., Morgan, J., Sonquist, J., \& Klein, L. (1973). Multiple classification analysis (2nd ed.). Ann Arbor, MI: University of Michigan Press.

Atchley, R. (1989). The continuity theory of normal aging. The Gerontologist, 29, 183-90.

Bandura, A. (1969). Social learning theory of identificatory processes. In D.A. Goslin (Ed.), Handbook of socialization theory and research (pp. 213-262). Chicago: Rand McNally.

Bandura, A., \& Walters, R.H. (1963). Social learning and personality developments. New York: Holt, Rinehart \& Winston.

Bouchard, C., Shepard, R.J., Stephens, T., Sutton, J.R., \& McPherson, B.D. (1990). Exercise, fitness and health: A consensus of current knowledge, Champaign, IL: Human Kinetics.

Bouchard, C., Shepard, R.J., \& Stephens, T. (Eds.) (1994). Physical activity, fitness and health; International proceedings and consensus statements. Champaign, IL: $\mathrm{Hu}-$ man Kinetics.

Bucher, C. (1974). National adult fitness survey: Some implications. Journal of Health, Physical Education and Recreation, 45, 25-28.

Csikszentmihalyi, M. (1997). Activity, experience, and personal growth. In J. Curtis \& S. Russell (Eds.), Physical activity in human experience: Interdisciplinary perspectives (pp. 61-88). Champaign, IL: Human Kinetics.

Curtis, J., \& Russell, S. (Eds.) (1997). Physical activity in human experience: Interdisciplinary perspectives. Champaign, IL: Human Kinetics.

Curtis, J., \& White, P. (1992). Toward a better understanding of the sport practices of francophone and anglophone Canadians. Sociology of Sport Journal, 9, 403-422.

Howell, F., \& McKenzie, J. (1987). High school athletics and adult sport-leisure activity: Gender variations across the lifecycle. Sociology of Sport Journal, 4, 329-346.

Kelly, J. (1980). Leisure and sport participation. In D. Smith \& J. Macaulay (Eds.), Participation in social and political activities (pp. 170-176). San Francisco: Jossey-Bass.

Malina, R.M. (1996). Tracking of physical activity and physical fitness across the lifespan. Research Quarterly for Exercise and Sport, 67(Suppl. 3), 48-57.

McPherson, B.D. (1998). Aging as a social process: An introduction to individual and population aging. New York: Harcourt Brace.

Montoye, H., Van Huss, W. \& Zuidema, J. (1959). Sport activities of athletes and nonathletes in later life. Physical Education, 16, 48-51.

Morgan, W., \& Montoye, H. (1984, July). Quality of life and health status of aging athletes and non-athletes: A twenty year longitudinal study. Paper presented at the Olympic Scientific Congress, Eugene, OR.

Nicholl, J., Coleman, P., \& Brazier, J. (1994). Health and healthcare costs and benefits of exercise, Pharmoeconomics, 5, 109-122.

Nicholl, J., Coleman, P., \& Williams, B. (1995). The epidemiology of sports and exercise related injury in the United Kingdom. British Journal of Sports Medicine, 29, 232238.

Nixon, H.L. II, \& Frey, J. (1996). A sociology of sport. Belmont, CA: Wadsworth.

Paffenburger, R.S., Hyde, R.T., Wing, A.L., \& Hsieh, C. (1986). Physical activity, all causes mortality, and longevity of college alumni. New England Journal of Medicine, 314, 605-613.

Powell, K.E., \& Dysinger, W. (1987). Childhood participation in organized school sports and physical education as precursors of adult physical activity. American Journal of Preventative Medicine, 3, 276-281. 
Quinney, A., Gauvin, L., \& Wall, A.E. (Eds.) (1994). Toward active living: Proceedings of the International conference on Physical Activity, Fitness and Health. Champaign, IL: Human Kinetics.

Rees, R.C., Andres, F.F., \& Howell, F.M. (1986). On the trail of the "turkey trotters": The effects of previous sports involvement and attitudes on commitment to and skill in running. Sociology of Sport Journal, 3, 134-143.

Spirduso, Q. (1995). Physical dimensions of aging. Champaign, IL: Human Kinetics.

van Mechelen, W., \& Kemper, H.C.G. (1995). Habitual physical activity in longitudinal perspective. In H.C.G. Kemper (Ed.), The Amsterdam Growth Study: A longitudinal analysis of health, fitress and lifestyle (pp. 135-158). Champaign, IL. Human Kinetics.

Vanreusel, B., Renson, R., Beunen, G., Claessens, A.L., Lefevre, J., Lysens, R., \& Eynde, B.V. (1997). A longitudinal study of youth sport participation and adherence to sport in adulthood. International Review for the Sociology of Sport, 32, 373-387.

Wankel, L. (1997). The social psychology of physical activity. In J. Curtis \& S. Russell (Eds.), Physical activity in human experience: Interdisciplinary perspectives (pp. 93-126). Champaign, IL: Human Kinetics.

Watkins, B.C. (1983). Secondary schools and their effects on continuing participation in physical activity. Unpublished doctoral dissertation, University of Oregon, Eugene.

White, P., \& Curtis, J. (1984). Age and sport participation: Decline in participation with age or increased specialization with age? In N. Theberge and P. Donnelly (Eds.), Sport and the sociological imagination (pp. 273-293). Fort Worth, TX: Texas Christian University Press.

White, P., \& Curtis, J. (1990). English-French Canadian differences in types of sport participation: A test of the school socialization explanation. Sociology of Sport Journal, 7, 347-369.

White, P., Curtis, J., \& McPherson, B. (in press). Age and physical activity among Canadian women and men: Findings from longitudinal national survey data. Journal of Aging and Physical Activity.

White, P., Young, K., \& Gillett, J. (1995). Bodywork as a moral imperative: Some critical notes on health and fitness. Loisir et Societe, 18, 159-182.

Yang, X. (1997). A multidisciplinary analysis of physical activity, sport participation and dropping out among young Finns, a 12-year follow-up study. Likes Research Reports on Sport and Health, 103.

\section{Acknowledgments}

We are grateful to Jay Coakley, Bob Ellsworth, Becky Beal, and Terry Stewart for helpful suggestions for our analyses. Also, thanks are due Statistics Canada for making the General Social Survey data available for analysis. 